JSACE $2 / 29$

Energy and Aesthetic Upgrading Interventions: Assessing Urban Block Renovation Scenarios

Received 2021/05/26 Accepted after revision 2021/09/02

\section{Energy and Aesthetic} Upgrading Interventions:

\section{Assessing Urban Block
Renovation Scenarios}

\section{Dimitra Tsirigoti", Dimitrios Zenginis, Dimitrios Bikas}

Aristotle University of Thessaloniki, Faculty of Engineering, Department of Civil Engineering, Laboratory of Building Construction and Building Physics, PO BOX 429, 54124 Thessaloniki, Greece

${ }^{*}$ Corresponding author: dtsirigo@civil.auth.gr

\section{$\Gamma$} Crossef http://dx.doi.org/10.5755/j01.sace.29.2.29176

The target towards carbon neutral cities emerges as a new way to mitigate the environmental pollution and the indisputable climate change, but it can also be the chance for the overall improvement of the quality of life by promoting the upgrading of the often low aesthetic quality of the urban environments. The objective of the research is to investigate renovation strategies at the city scale that will not only reduce the energy demand, but they will also promote the improvement of the city's aesthetics. Two different typologies of urban block forms of the Greek city are examined, and four scenarios of renovation interventions are analysed according to energy and aesthetic criteria.

The heating and cooling load demand is calculated through simulations for the four renovation scenarios which include:

- The improvement of the thermal insulation of the building's shells.

- The use of phase change materials.

- The construction of green roofs.

The integration of passive solar and shading systems.

The findings of the research prove that the energy interventions at the urban block scale can define the degree of efficiency in the energy performance level without compromising aesthetics, as the added value resulting from higher aesthetics is a basic criterion for the overall improvement of the quality of life.

Keywords: energy efficiency, urban block form, energy renovation, city aesthetics, PCM, green roof, passive solar systems.

\section{Introduction}

Sustainable urban development has been a major target during the last decades. As cities are complex systems, their sustainability depends on the development in multiple levels. Therefore, different approaches have been proposed towards a sustainable urban development. Among these approaches and strategies are the examination of sustainable urban forms, the implementation of sustainable transportation, the integration of renewable energy in the urban environment, the promotion of recycling, the waste and water management etc.

At the same time the institutional framework in many countries has also been targeted in promoting the sustainability of the urban environments, especially in the building sector where the majority of countries have set stricter building codes fostering energy efficiency following the recast European Directive 2010/31/EU on the energy performance of buildings (Van Oorschot, Hofman, and Halman 2016) and Directive 2012/27/EU on energy efficiency (European Union 
2012). The institutional framework for the energy efficiency of buildings is also recently being reformed under the recommendation 2016/1318 of the European Commission (European Union Commission 2016) for the promotion of nearly zero energy buildings and the revised Energy Performance of Buildings Directive 2018/844 (EPBD 2018). The EU aims to be climate neutral until 2050 by proposing a European Climate Law to turn this political commitment into a legal obligation (A European Green Deal | European Commission n.d.).

Under this direction, there have been many efforts to upgrade the existing building stock as there is a large amount of buildings which has been built in the past with low energy efficiency standards. On 14 October 2020 the Commission published a new strategy for renovation called "A Renovation Wave for Europe - Greening our buildings, creating jobs, improving lives" (COM(2020)662) (Renovation Wave | Energy n.d.). Moreover, there is a broad research for tools, strategies and campaigns for existing buildings targeting to a zero energy development (R2Cities: Residential Renovation towards Nearly Zero Energy Cities n.d.), (Renovate Europe n.d.), climate neutral cities (CLUE n.d.) or innovative renovation strategies for building facades (Tsikaloudaki et al. 2019). In addition, except from the energy efficiency, other aspects of building renovation are often considered for the existing buildings stock. Low construction quality and low aesthetics are often apparent in low energy efficient buildings.

In most European cities there is a large amount of building stock both in the central areas and in the periphery of large cities which has been built in previous decades which has not been maintained properly for a longtime and in most cases, it cannot meet the contemporary needs in terms of quality of life, energy efficiency, economic viability and environmental protection (Robust and Reliable Technology Concepts and Business Models for Triggering Deep Renovation of Residential Buildings in EU | 4RinEU Project | H2020 | CORDIS | European Commission n.d.). Apparently, a sustainable approach should target at an integrated renovation of existing buildings as, on the one hand, the majority of city centers have already been built and on the other hand, a new building replacing a demolished one would need many years to counterbalance the embodied energy loss from the demolition (Craun 2012).

The evaluation of the building stock has been a challenging issue during the past few years.

There is a broad research focusing on the energy consumption of the residential building stock (Sabunas and Kanapickas 2017) and on the investigation of renovation interventions of single family houses taking into account the target for nearly Zero Energy Buildings (nZEB) (Serghides et al. 2015), or in apartment buildings, including scenarios for green roofs (Karteris et al. 2016) or sunspaces (Fotopoulou et al. 2018).

Many investigators have been trying to develop methods for evaluating the existing building stock of cities through the definition of building typologies (Aksoezen et al. 2015), building archetypes (Mata, Sasic Kalagasidis, and Johnsson 2014), (Caputo, Costa, and Ferrari 2013), urban block typologies (Tsirigoti and Tsikaloudaki 2018). Other researches have proposed methodologies for defining retrofit strategies with the aid of data-driven approaches (Ali et al. 2020) or other statistical methods (Fracastoro and Serraino 2011) in order to reduce the complexity of the urban tissue and the large number of building typologies of cities.

Among the various characteristics used in order to categorize the building stock is the age and the construction type of buildings, the building height, the surface to volume ratio, the floor area ratio (FAR) and other geometry factors such as road width, height to width ratio $(\mathrm{H} / \mathrm{W})$, plan proportions etc. Several studies focus on all periods of construction including heritage (Energy Renovation of Heritage Buildings | Interreg Europe n.d.) or listed buildings, while others mainly focus on the non-protected building stock.

Retrofit strategies include building shell interventions in order to reduce the heat flow through 
the building elements or more advanced interventions including lighting and heating system replacement, Renewable Energy Sources (RES) installations or even more innovative or hybrid technologies.

In the first category the most common method used is the thermal insulation of the buildings' exterior surfaces. The renovation strategies could target on both the horizontal and vertical exterior surfaces, but the most common technology used is the addition of exterior thermal insulation composite systems (ETICS) in building facades and roofs.

Concerning the energy renovation of facades, except from the conventional type of ETICS, there are also passive techniques in order to increase solar heat gains and the addition of shading for reducing cooling load.

The addition of attached sunspaces is the most commonly used passive solar technology in building renovation, followed by the construction of double skin facades. Green facades have also been applied in many cases in order to improve the energy efficiency of buildings and to provide a new greener aesthetic in cities.

Green roof construction in existing buildings has also been examined as an energy upgrade renovation strategy of the building shell which can at the same time reduce heating and cooling load and improve the urban microclimate of cities.

A more innovative energy renovation technology of the building shell has been the use of Phase Change Materials (PCM) which could increase the building's thermal mass without adding significant weight to the construction.

In existing buildings not all interventions that can be used in new buildings are applicable, because it is not always easy to integrate all systems in existing structures due to structural or constructional barriers.

In the second category there are several kinds of installations of more efficient HVAC systems with fuels with less pollutant emissions, and several types of renewable energy sources systems, such as photovoltaics, ground source heat pumps (GSHP) etc.

There are also hybrid systems combining both approaches to maximize the efficiency of the interventions and to provide an integrated method for retrofitting buildings (aesthetic, lighting, energy, acoustics etc.) (E2VENT H2020 Project n.d.), (Ferrante et al. 2019). Most of the hybrid approaches target on specific energy rating or even on nearly zero energy buildings.

These technologies and strategies are mainly targeted to the renovation of individual buildings resulting in a fragmented renovation of the building stock. This leads to a low impact of the renovation efforts on the overall city and on the inability to plan a wide scale renovation strategy at the city scale. Another issue resulting from this fragmented renovation is the low aesthetics of the city. On the one hand, there is no uniform renovation vision and each building is renovated without taking into account the condition of neighboring buildings and the overall image of the city and, on the other hand, the different strategies of renovation designed in adjacent buildings create an even larger uniformity on the appearance of the façades.

This is why there have been efforts to apply renovation strategies in a larger scale (Mastrucci et al. 2014), (Serrano-Jimenez, Barrios-Padura, and Molina-Huelva 2017), (Rovers, n.d.) in order to improve the overall quality of the building stock at urban scale and to design renovation in a more sustainable way in terms of promoting at the same time energy efficiency, quality of life, aesthetic quality and economy of scale.

\section{The Form and the Energy Profile of the Greek Building Stock}

The Greek city consists of a variety of building forms according to the period of construction, the distance from the city center and the building use. In most cases the central areas present higher 
densities than more distant areas and the buildings form a continuous urban tissue as they are attached to each other. On the other hand, urban tissues appear to be more discontinuous in the periphery of city centers, while building heights remain relatively high in both cases. In even more distant areas, the urban tissue has lower building heights and lower density.

Except from the form of historic buildings, most building forms which have been built after the 50's have been largely defined by the building regulations' restrictions and rules. The multifamily apartment building, which is the most common building type met in the Greek city after the 50's, can be easily analysed by examining the regulatory limitations and restrictions of each period.

Even though the architectural form of the city can significantly vary, many building types follow common rules of form and geometry. The apartment buildings are characterized by typical floor plans. The ground floor has either a larger height when it has a commercial use, or it is elevated from the ground by $1.5 \mathrm{~m}$ when it houses an apartment. As a result of the typical floor plan, the facades also present a typical distribution of openings which is repeated in all typical floors. Finally, balconies have also typical form and dimensions in all floors. This means that the form of the Greek city in its best or worst architecture is characterized by a kind of uniformity resulting from the square urban grid and the dominant building type which has been developed as a result of a series of building regulations. As there are very few unbuilt spaces in the city centers, and the majority of existing buildings have been built between 1950 and 1980 it can be easily concluded that the construction of these buildings cannot meet the contemporary qualitative requirements in order to cover users' needs and contemporary criteria of quality.

The main constructional system of these buildings is reinforced concrete load bearing structure and double brick masonry walls. As far as it concerns energy consumption most of these buildings present low performance as they have been built during periods where thermal insulation of the building shell was mandatory or even in earlier periods when the contemporary thermal insulation materials were unknown.

In addition, the overall construction and aesthetic quality remains low due to the fact that all interventions that have been made on the buildings since their original construction have been implemented in a random and arbitrary way without any central planning or design concept. These, interventions can be grouped into two main categories:

First, several building elements have been added on building facades over the years, such as window shutters, shading overhangs, mechanical equipment for heating, cooling and hot water etc.

Second, old and degraded materials and building elements have not been replaced since their original construction or they have spontaneously been replaced in some apartments by the owners while in others they remain in their original form. Broken shading overhangs, eroded railings, or partially damaged façade claddings or exterior coatings on building facades define the appearance of many Greek buildings.

As it can be easily concluded, the built environment of the Greek city faces issues of degradation due to three main factors: low construction quality, low energy performance and low aesthetic quality. The lack of renovation for many years has led to the emergent need for a renovation strategy that will promote the improvement of these three parameters at the same time in order to upgrade the quality of the built environment in the Greek city.

During the past decade the Greek state has promoted some efforts to improve one of these three parameters -the energy performance of these buildings- mainly through economic incentives, which were imposed in order to comply with the European Directives for the energy performance of buildings. All efforts intended to improve only the energy performance of buildings without considering any other aspects of improvement of the overall quality of buildings and especially their aesthetic quality. On the contrary, many of these interventions contributed to a further degradation of the aesthetic and construction quality of the buildings. 
The effort to improve the energy performance of buildings in Greece begun in 2008 with the funding for the replacement of old air conditioning installations in residencies. Split unit systems were replaced by new ones in the same random positions as the old ones.

The installation of solar thermal collectors for domestic hot water became more and more common on the rooftops of private houses or apartment buildings which were also promoted by state funding. Subsidies for the installation of domestic photovoltaics were also promoted by the state to promote RES. Solar thermal collectors or photovoltaics were installed on flat or inclined roofs in a random way. The promotion of replacement of existing central oil-based heating systems with natural gas local heating systems followed the same irrational positioning of the natural gas units on the buildings facades as well.

In 2010, after the implementation of the National Regulation for the Energy Performance of Buildings (KENAK) (Greek Regulation for the Energy Performance of Buildings, FEK 2367 2017), followed several programs with subsidies for upgrading the energy performance of buildings which among others included building shell thermal insulation interventions, shading systems installation or replacement of older ones.

In 2011 the "energy saving in the housing sector program I" was launched and in 2018 and in 2019 followed the "energy saving in the housing sector program II". Recently, the "energy saving and energy autonomy in the housing sector" has been announced.

All these interventions, repeated in almost all buildings, resulted in even lower aesthetic image of the city, which in addition the degradation of many other elements of the facades such as railings, awnings and window casements have led to a crucial question for the future interventions targeting to the improvement of the energy performance of buildings.

\section{Scope and Objective}

The scope of the research is to investigate smart renovation strategies at the city scale which can contribute at the same time on the limitation of carbon gas emissions, the improvement of the city's aesthetics and the improvement of the overall quality of the city. The three main objectives of the research are:

a. To prove that a sustainable energy performance renovation strategy could be more efficient if implemented at the urban block scale instead of the building scale, as it can provide added value on the aesthetics and building construction quality.

b. To investigate ways for the design and implementation of energy upgrading strategies on urban blocks.

c. To assess and compare the energy savings of the proposed renovation strategies.

The basic research question is if the tools targeted to the future energy performance improvement of buildings could also be used as a challenge to improve the overall quality of the buildings, taking into account the aesthetic parameter and the improvement of not only energy efficiency but also of the overall quality of construction. The research intends to propose ways of transforming the energy improvement of buildings into a challenge for the holistic regeneration of the cities' overall quality.

For the scope of the study, two typical urban blocks with different form and geometry are analyzed in order implement well known energy improvement strategies which can as well promote the aesthetic upgrading of the buildings.

The research intends to prove that aesthetic and energy improvement strategies and technologies, applied not in individual buildings but in urban blocks, can be combined in order to promote an integrated regeneration of the city's quality. The recent recast energy performance regulation and the economic incentives it can provide to the owners if used for the design and implementation of interventions at the urban block scale can provide the opportunity for a holistic regeneration of the Greek cities. 


\section{Description of the Analysed Cases}

As mentioned above, two models of typical urban blocks are analysed in order to implement several renovation strategies and to compare their efficiency according to form and geometry factors. The first urban block is of discontinuous form, meaning that buildings are detached, while the second urban block is of continuous form, with buildings attached to the neighboring buildings in both their sides. The plans and 3D drawings of the two examined urban bocks are presented in Fig. 1 and Fig. 2, while parameters of geometry and size are presented in Table 1.

\begin{tabular}{|c|c|c|c|c|c|c|c|c|c|}
\hline UB & $\begin{array}{c}\text { Plot } \\
\text { Surface } \\
\left(\mathrm{m}^{2}\right)\end{array}$ & $\begin{array}{c}\text { Exposed } \\
\text { Shell } \\
\left(\mathrm{m}^{2}\right)\end{array}$ & $\begin{array}{c}\text { Volume } \\
\left(\mathrm{m}^{3}\right)\end{array}$ & $\begin{array}{c}\text { Road } \\
\text { Width } \\
(\mathrm{m})\end{array}$ & $\begin{array}{c}\text { Height } \\
(\mathrm{m})\end{array}$ & $\begin{array}{c}\text { N. of } \\
\text { Floors }\end{array}$ & $\begin{array}{c}\text { Coverage } \\
\text { Ratio }\end{array}$ & $\begin{array}{c}\text { Floor } \\
\text { Area } \\
\text { Ratio }\end{array}$ & $\begin{array}{c}\text { Surface } \\
\text { to Volume } \\
(\mathrm{S} / \mathrm{V})\end{array}$ \\
\hline 1 D & 3608 & 8965 & 17271 & 10 & 13 & 4 & 0.4 & 1.4 & 0.5 \\
\hline 2 C & 6864 & 33835 & 102391 & 10 & 22 & 7 & 0.7 & 4.7 & 0.3 \\
\hline
\end{tabular}
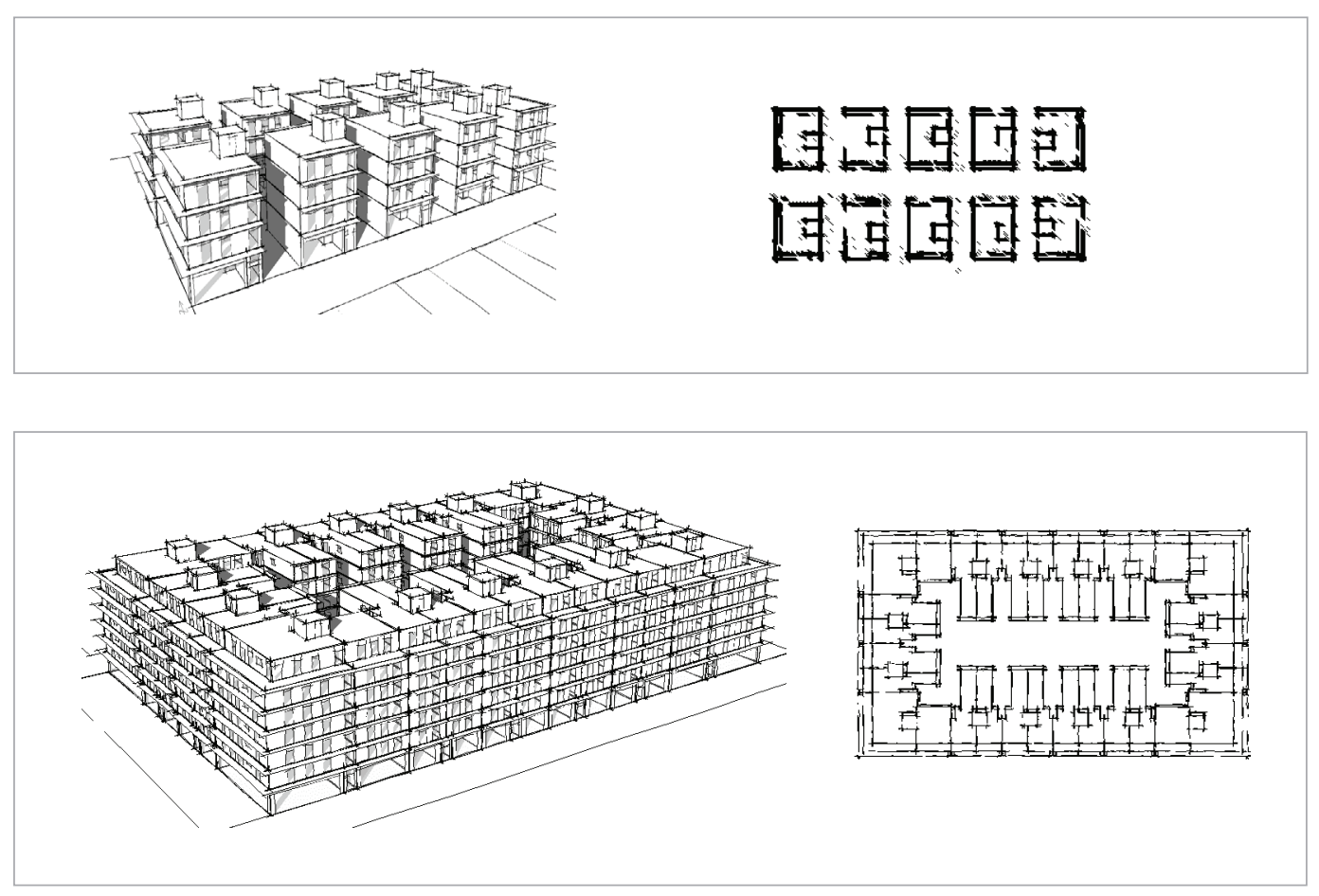

Fig. 2

$3 \mathrm{D}$ representation drawing and plan of urban block typology 2

Several assumptions about the orientation, road width and climatic conditions have been made in order to eliminate these parameters from the results, making conclusions about form and geometry clearer. Both urban blocks are considered to have the same orientation $\left(0^{\circ}\right)$ meaning that the north axis is parallel to the narrow side of the urban block plan. The road width for all the streets surrounding the urban block is $10 \mathrm{~m}$, while the two urban blocks are situated in Greek climatic zone C. Greece is divided in four climatic zones (A, B C and D) according to the national energy performance of buildings regulation, with zone $A$ representing the warmest climatic zone while zone $D$ the coldest (Greek Regulation for the Energy Performance of Buildings, FEK 2367 2017). In detail, the investigation is carried out for the climatic conditions of the city of Thessaloniki, which corresponds to a Mediterranean climate with hot and quite dry summers and relatively dry winters. Monthly average temperatures and monthly solar radiation values for the city of Thessaloniki are presented in Fig.3 ( $a$ and b). 
Fig. 3

a. Monthly average temperature and b. Monthly solar radiation for the city of Thessaloniki

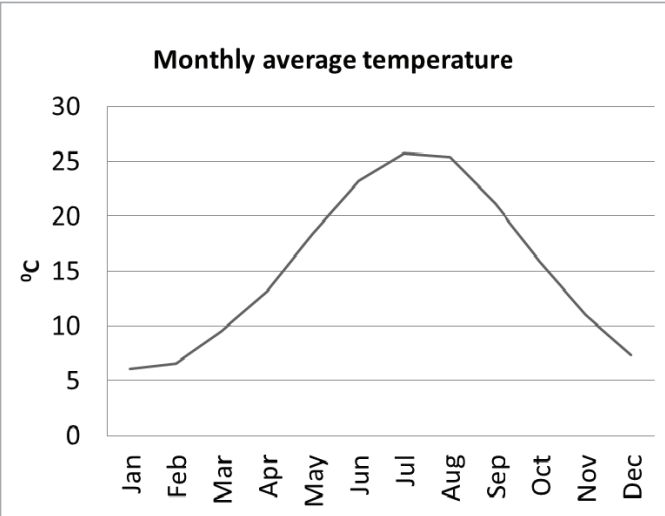

a

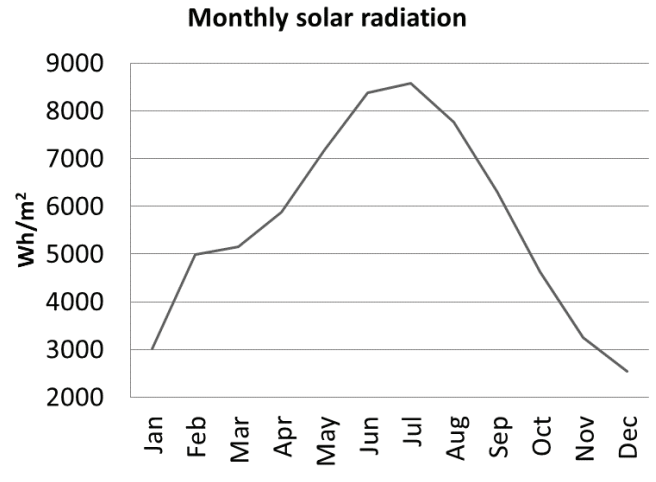

b

The research investigates the way the urban block form and geometry can affect the performance of energy upgrading strategies and installations. Therefore, four different energy upgrading scenarios are analysed for each urban block according to energy efficiency criteria:

1. Building shell thermal insulation.

2. Green roof construction.

3. Smart materials use (Phase change materials).

4. Passive solar systems (sunspaces).

The four scenarios are also designed according to three main aesthetic criteria:

- The vertical organization of all mechanical installations in specific positions of the building facades.

_ The pre-installation design of solar collectors and / or photovoltaic panels.

- The unified constructional and architectural form for sun spaces and shading devices.

In the first axis of the research, all the above-mentioned interventions are designed and simulated in order to calculate heating and cooling demand. The research intends to assess each one of the four interventions in order to define the degree that it can contribute in the reduction of energy demand for heating and cooling. The EnergyPlus 9.2.0 software, which is one of the most commonly used programs for modeling the energy performance in buildings, has been used for the energy simulations. All the simulations have been run for one year, using the standard IWEC weather files of Thessaloniki city. With regard to the heat balance algorithm, the conduction transfer function is employed for all the investigated scenarios except for the PCM because of its nonlinear behavior. Thus, in case of the PCM, the conduction finite difference algorithm (ConFD), that provides the opportunity to simulate materials with variable properties such as PCM, was used. Within this respect, the ConFD method is coupled with an enthalpy-temperature function to simulate phasechange processes. Furthermore, the default ConFD model with 20 time steps per hour is used to assess the annual energy demand for all the examined cases, as recommended by (Tabares-Velasco, Christensen, and Bianchi 2012).

In the second axis of the research, an aesthetic approach of the interventions in an overall urban block architectural design is proposed for each urban block. The design intends, on the one hand to prove that similar energy upgrading interventions can be applied at the urban block scale (as opposed to individual buildings) without compromising the aesthetic quality of the city and on the other hand it intends to give directions on how to develop guidance for developing policies and strategies in order to promote the energy upgrading interventions according to the urban block form and geometry. 


\section{Buildings' construction and operation conditions}

Several assumptions have also been made for the buildings' construction and operation parameters. It has been assumed that all buildings have residential use on all typical floors and a retail use on the ground floor, meaning they have a similar operation and occupation schedule, respectively.

According to the Greek building legislation framework, residence and retail are occupied $18 \mathrm{~h}$ and 9h per day, respectively. In addition, both residence and retail zones are temperature - controlled using the ideal load HVAC system, which removes the heat at $100 \%$ efficiency in order to supply conditioned air to the zones, meeting the load demands. Therefore, HVAC system schedules were matched to the occupancy schedules and a dual setpoint thermostat was selected to control the indoor temperature. The thermostat setpoint was set to $20^{\circ} \mathrm{C}$ for heating and $26^{\circ} \mathrm{C}$ for cooling, as recommended by the Greek regulation for the energy performance of buildings (Greek Regulation for the Energy Performance of Buildings, FEK 2367 2017) for residential and retail building uses. As far as ventilation is concerned, a constant rate of $1.25 \mathrm{ACH}$ and $1.75 \mathrm{ACH}$ is considered for hygienic purposes during the occupied hours in terms of residence and retail, respectively, while an additional night ventilation is introduced between 22:30 and 07:00.

In addition, all buildings also have the same constructional system of concrete load bearing elements and brick masonry walls (which is the most typical construction system used in the Greek apartment buildings).

\section{Description of the energy upgrading intervention scenarios}

First, a base case scenario has been considered in order to be compared with all the intervention scenarios. For the base case scenario all building elements (walls, roofs, beams and columns) have been assumed to be non - insulated, having poor airtightness, with an infiltration rate equal to $2 \mathrm{ACH}$ during the whole day.

\section{a. Thermal insulation scenario}

The first scenario includes the conventional thermal insulation of the building shell, according to the minimum permitted values of the national energy performance of buildings regulation (KENAK) for refurbished buildings, as well as the buildings' airtightness improvement, as the infiltration rate is considered equal to $1 \mathrm{ACH}$. Additional interventions are considered in the other three scenarios. The $U$-values of all building elements for the base case scenario and for the four upgrading scenarios, where thermal insulation is added on the building shell, are presented in Table 2.

\begin{tabular}{|c|c|c|c|}
\hline \multirow{2}{*}{$\begin{array}{l}\text { Building } \\
\text { element }\end{array}$} & \multirow{2}{*}{ Description } & Base case scenario & Thermal insulation scenarios \\
\hline & & U-value $\left(\mathrm{W} / \mathrm{m}^{2} \mathrm{~K}\right)$ & $\mathrm{U}$-value $\left(\mathrm{W} / \mathrm{m}^{2} \mathrm{~K}\right)$ \\
\hline \multirow{2}{*}{ Walls } & Exterior reinforced concrete elements & 3.25 & 0.45 \\
\hline & Exterior brick masonry & 1.72 & 0.45 \\
\hline \multirow{3}{*}{ Slabs } & Interior R.C. slabs & 2.74 & 2.74 \\
\hline & Flat roof & 2.11 & 0.40 \\
\hline & Reinforced concrete slab on ground & 2.65 & 0.75 \\
\hline \multirow{2}{*}{ Openings } & Windows & 5.81 & 2.80 \\
\hline & Doors & 5.81 & 2.80 \\
\hline
\end{tabular}

Table 2

Material's thermal properties description for the base case scenario and for the thermal insulation scenarios 


\section{b. Green roof scenario}

As the existing buildings' structural system has not been designed to carry the loads of a green roof, for the second scenario an extensive green roof type has been considered for all the flat roof surfaces of the urban block. Extensive green roof types are thin lightweight roof systems that typically have a planting media measuring 6 to $20 \mathrm{~cm}$. For the simulations, a $9 \mathrm{~cm}$ soil has been considered, corresponding to a $U$-value of $0.3 \mathrm{~W} / \mathrm{m}^{2} \cdot \mathrm{K}$.

\section{c. Phase change materials scenario}

For scenario 3 the Phase Change Materials (PCM) taken into account are embedded in a $3 \mathrm{~cm}$ smart board in all the exterior walls and all walls facing a non-heated space, in order to both reduce the energy demands and to improve the indoor thermal comfort. For the continuous form urban block PCM board have also been placed in the adjacent walls between buildings in both sides. Regarding the PCM thermophysical properties, a smart board with a phase change temperature of $25{ }^{\circ} \mathrm{C}$, a phase change enthalpy equal to $110 \mathrm{~kJ} / \mathrm{kg}$ and a thermal conductivity $\lambda=0.23 \mathrm{~W} / \mathrm{m} \cdot \mathrm{K}$ has been considered.

\section{d. Passive solar and shading scenario}

The fourth scenario concerns the installation of passive solar and shading systems. Sunspaces are proposed for balconies, and the buildings' last floor recession and the design of shading as well.

They are closed volumes, constituted by transparent surfaces, adjacent to the buildings which reduce heating load through solar gains. The glass material is assumed to be the same as the glass material of the transparent elements of the buildings in scenarios 1-4, with a $U$-value equal to 2.8 $\mathrm{W} / \mathrm{m}^{2} \cdot \mathrm{K}$, as specified in Table 2, and a solar heat gain coefficient equal to 0.45 . Furthermore, in order to avoid summer overheating, sunspaces are modelled to be opened between the middle of May and the end of September as well as to be equipped with shading devices. In detail, for an efficient use of solar heat gains, sunspaces transparent surfaces are provided with an external movable shading device. From October to the middle of May, these devices are pulled back in order to maximize solar gains. On the contrary, from the middle of May to October, the shading devices are lowered with slats set to 90 degrees to minimize solar heat gains.

\section{Design of the Interventions}

For the improvement of building aesthetics four main criteria were applied:

First, the arrangement of mechanical installations on building facades and the design of vertical cladding elements behind which all installations (air conditioning units / natural gas units etc.). The appropriate ventilation is provided by using perforated cladding or horizontal blinds on steel structure.

Second, passive solar systems in the form of sun spaces are used in order not only to improve energy performance, but also in order to provide a common structure for shading elements which are intended to replace the existing awnings. Shadings systems in balconies are also used often not only for shading needs, but also in order to protect from the wind, rain, dust or even for providing a more private space protected from the sight of neighbors.

Third, solar collectors for hot water and photovoltaics are also considered in terms of a pre-installation design in roof tops. This strategy intends to prevent future random positioning of such installations and to create a ready to use substructure which will be integrated in the urban block form.

Fourth, green roofs have also been designed on rooftops in order to take into account the previously mentioned installation of solar systems on the rooftops and to produce a unified aesthetic quality on the urban blocks skyline. 
All the above-mentioned aesthetic interventions were adjusted in the form and geometry of each of the two examined urban blocks and are presented in detail in the following sections.

\section{a. Urban block 1}

The discontinuous typology examined is characterized by the fact that the front and rear façade have openings and balconies while the side facades have a larger opaque surface as they have very few small openings or no openings at all, depending on the position of the staircase. This is the reason why these side walls have been chosen as more appropriate for placing all the necessary mechanical equipment. A large surface of the façade remains opaque and is considered suitable for placing a second skin, which is designed in an appropriate distance from the existing wall, in order to have enough space for the mechanical equipment that is intended to cover.

For the sunspaces positioning, a sun study has been performed in order to define the most effective way to design these spaces. As sun spaces are supposed to be deactivated during the summer months, by opening all their façade transparent leaves, the sun study was performed for the heating period. The direct solar availability for the $21^{\text {st }}$ of December has been considered (Fig. 4) and as it is obvious, only the south oriented last floor balconies of the buildings have direct sunlight during December. Therefore, the sunspaces have been designed only in these balconies (Fig. 5). However, in the corners of the urban blocks, due to the geometry of the crossing streets sunspaces have been proposed for the south-east and south-west balconies in all floors. These sunspaces might not be as effective in terms of solar gains, but they can still contribute, and they can also function as a restraint zone for heat loss.
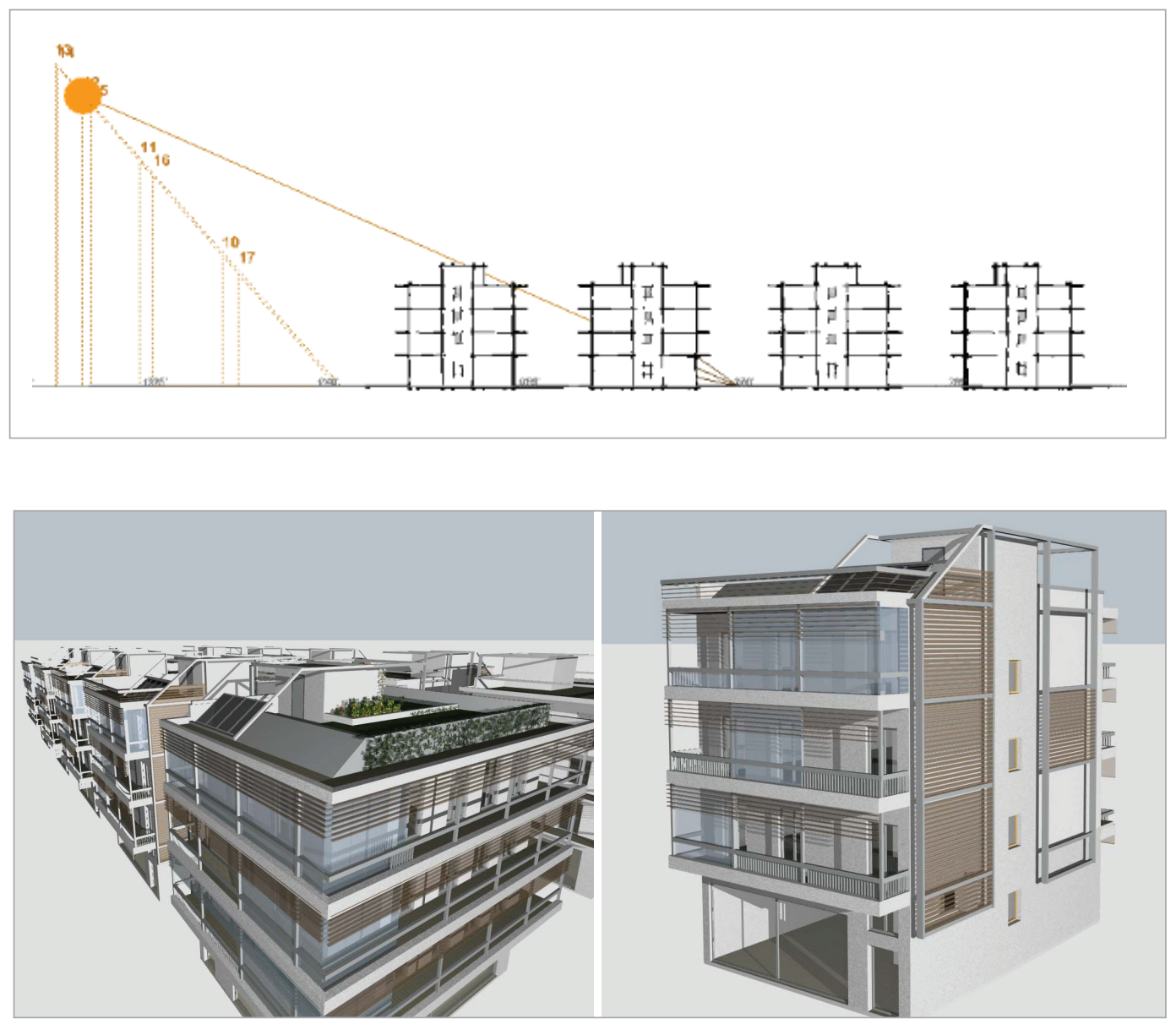

Fig. 4

Sun study showing the sun position the 21 st of December at noon

Fig. 5

Perspective view showing interventions in the urban block typology 1 for corner and middle positioned buildings 
Green roofs are designed on the rooftop surface of each building and some pergolas for climbing plants are also added in order to provide shading.

Solar collectors and photovoltaic panels, as already mentioned before, are not included in this study in terms of energy efficiency as they are not a part of the building shell, however they are considered as a possible future installation on the rooftops which might influence the aesthetic appearance of the city. In most cases there are no rules for their installation (except from the need to be inclined in order to achieve maximum efficiency) and they are installed in random positions resulting not only on the bad aesthetics of the fifth façade of the building (e.g. the flat roof), but also on the inefficient utilization of the surface of the roof. The situation is similar with the residential photovoltaics which cover the rooftops of buildings altering the aesthetic of the city to the worse.

Solar collectors or photovoltaic panels pre-installation surfaces have been designed on the rooftops of the buildings. The surfaces are inclined according to the need for maximum direct solar radiation $\left(30^{\circ}\right)$ and they are positioned in the perimeter of the rooftops to leave the space unified for other uses (including green roof installation).

\section{b. Urban block 2}

In the continuous typology of urban block 2 which is examined, in contrast to the discontinuous form (urban block 1), the buildings are attached to each other forming a unified façade which has openings and balconies both towards the street and towards the uncovered space at the center of the urban block (inner court). However, the façade elements are interrupted by a regulatory limitation which imposes the distance of balconies from the plots side boundary. According to this restriction the urban block façade has vertical opaque surfaces between the buildings extended in all floors and having a $2 \mathrm{~m}$ width. This space could be appropriate for installing all mechanical equipment which can be hidden behind the construction of a second skin extending in all floors between the buildings' balconies.

For the sunspaces positioning, a sun study has been performed for this typology as well in order to define the most effective way to design these spaces. The direct solar availability for the $21^{\text {st }}$ of December has been calculated as presented in Fig. 6 and, as it is obvious, only the last two floors of the buildings have direct sunlight during December. Therefore, the sunspaces for the reduction of heating loads have been designed only in these floors.

\section{Fig. 6}

Sun study showing the sun position the 21 st of December at noon

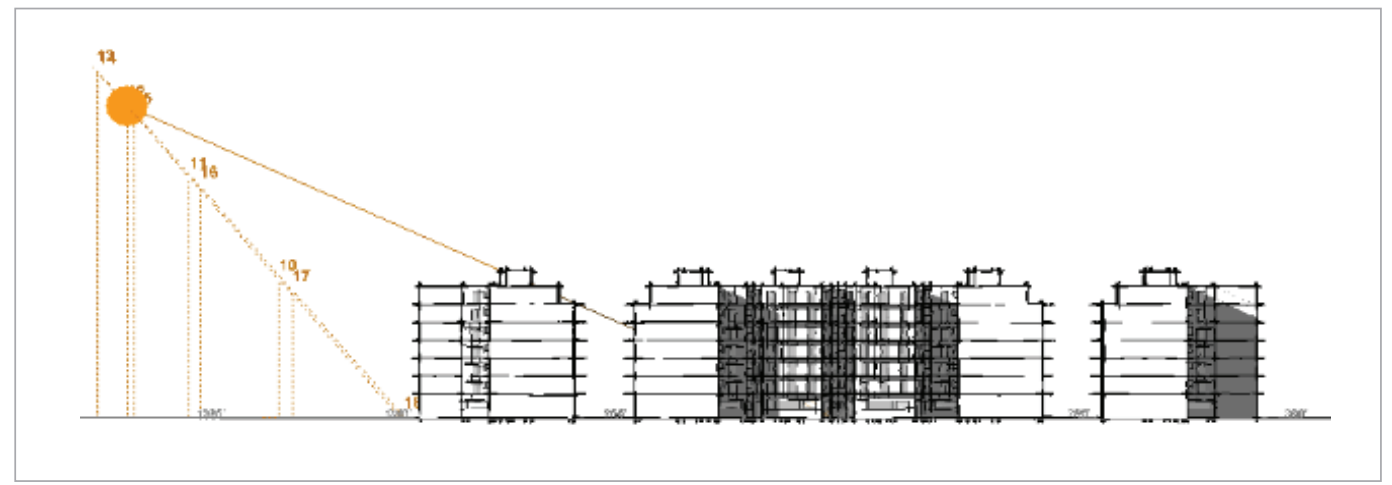

It should be noted that in this typology the last floor is recessed from the subjective floor and the geometry of the sunspace follows the geometry of the recession in order to comply with the regulatory restriction which imposed the recession of the last floor in the first place. For this reason, the sunspace is designed with inclined roof surfaces which besides the morphological reasons should also contribute on the efficiency of the sunspaces, as the sun rays hit the inclined glass more vertically (Fig. 7). 


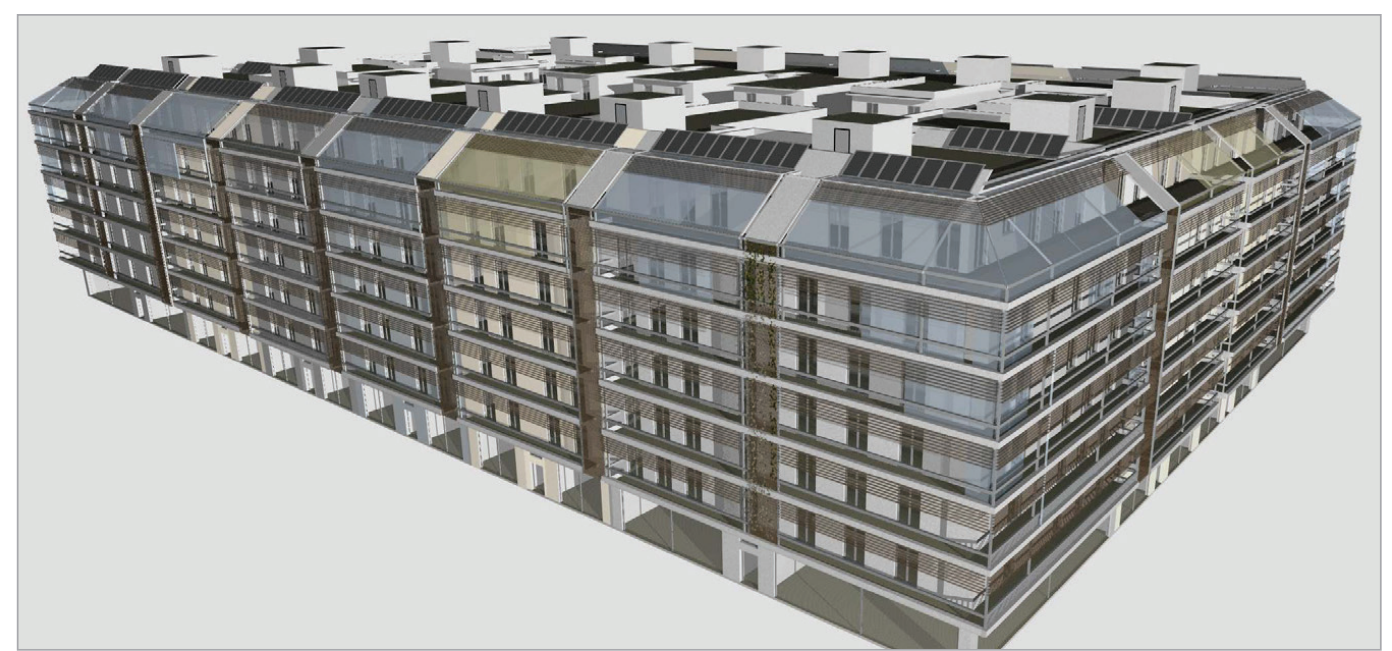

The design of the sunspaces in the last floor of this typology includes sunspaces in all orientations as these floors have increased heat losses. The last floor has always larger heat losses from the building shell compared to inferior floors due to the upper slab facing the interior. In this case the last floor has a recession which increases the surface of the exposed shell even more due to the geometry of the recession. The north facing buildings of the urban block are in an even more disadvantaged situation as solar availability is low due to orientation. Therefore, the sunspaces are designed mainly as heat restraint zones as in the case the orientation (north oriented facades) of the building does not favor passive solar gains. This choice has also architectural advantages as owners of these last recessed floors often construct illegal shading overhangs, awnings or even pergolas as these verandas suffer from the exterior climatic conditions (wind, rain, sun) in which they are exposed due to the fact that they are in a height where normally wind speed and sun radiation is higher and rainfall is harder as there are no obstructions from the neighboring buildings at this level. In the subjective floor the sunspaces' design follows the same geometry as in typology 1 including sunspaces in all balconies for the fifth floor and in the corners of the urban block as well.

Solar collectors or photovoltaic panels' pre-installation surfaces have been designed inclined according to the need for maximum direct solar radiation on the rooftop's south perimeter in an analogous way as in urban block typology 1 . These surfaces are also a safety boundary towards the rooftops edge (replacing existing railings). Green roofs are designed, on the rooftops surface of each building in the remaining free space.

\section{Energy Efficiency Assessment of the Interventions}

First the heating and cooling load demand has been calculated for the base case scenario of each one of the two urban block typologies. Then, the heating and cooling load demand has been calculated for each one of the four scenarios of the two examined typologies.

The results of the heating and of the cooling demand of the base case, compared to the four scenarios for the two urban blocks, are presented in Fig. 8 and Fig. 9.

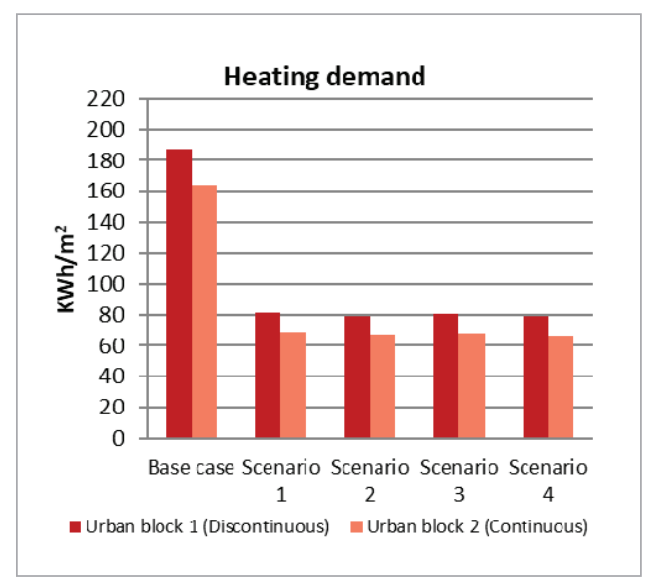

Fig. 7

Perspective view showing interventions in the urban block typology 2

\section{Methods}

\section{Fig. 8}

Comparison of the heating demand between the continuous and the discontinuous urban block form for all the examined scenarios 


\section{Fig. 9}

Comparison of the cooling demand between the continuous and the discontinuous urban block form for all the examined scenarios

Fig. 10

Comparison of the total demand between the continuous and the discontinuous urban block form for all the examined scenarios
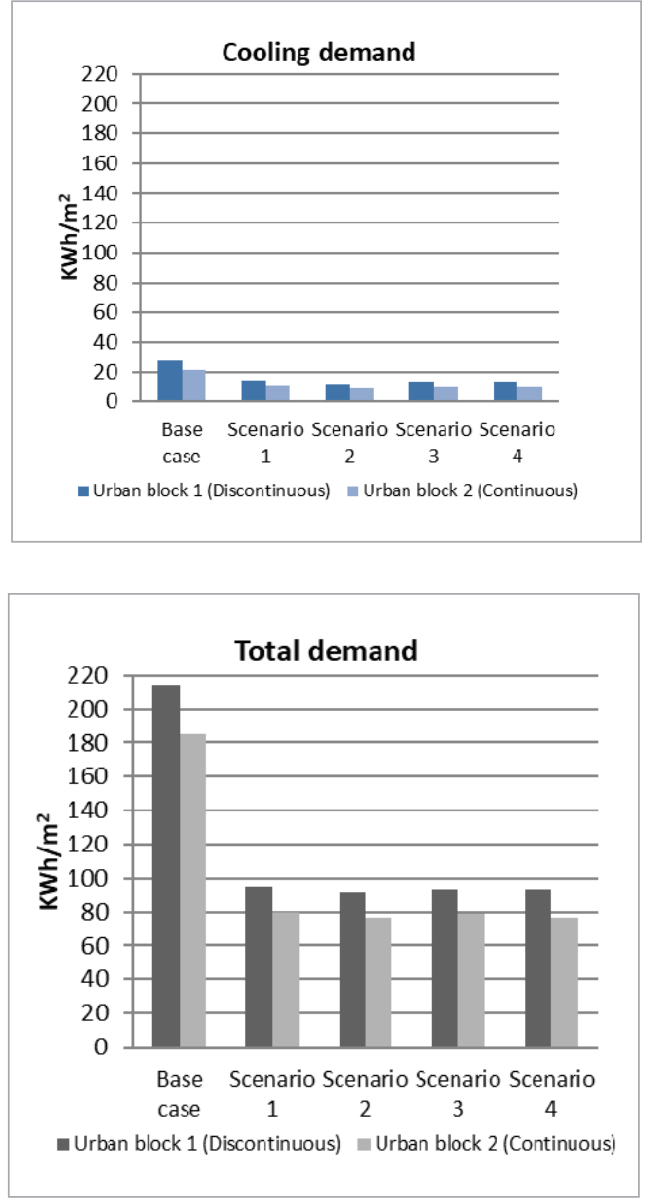

For UB1 heating demand is calculated to be $187.4 \mathrm{KWh} / \mathrm{m}^{2}$ for the base case scenario and it is reduced to $81 \mathrm{KWh} / \mathrm{m}^{2}, 79.0 \mathrm{KWh} / \mathrm{m}^{2} 80.2$ $\mathrm{KWh} / \mathrm{m}^{2}$ and $79.3 \mathrm{KWh} / \mathrm{m}^{2}$ for scenario $1,2,3$, and 4 respectively. Cooling demand is calculated to be $27.1 \mathrm{KWh} / \mathrm{m}^{2}$ for the base case scenario and it is reduced to $14.0 \mathrm{KWh} / \mathrm{m}^{2}, 12.2 \mathrm{KWh} / \mathrm{m}^{2}$, $13.2 \mathrm{KWh} / \mathrm{m}^{2}$ and $13.3 \mathrm{KWh} / \mathrm{m}^{2}$ for scenario 1,2 , 3 , and 4 respectively.

For UB2 heating demand is calculated to be 164.0 KWh/ $\mathrm{m}^{2}$ for the base case scenario and it is reduced to $68.5 \mathrm{KWh} / \mathrm{m}^{2}, 67.2 \mathrm{KWh} / \mathrm{m}^{2} 68.4$ $\mathrm{KWh} / \mathrm{m}^{2}$ and $66.4 \mathrm{KWh} / \mathrm{m}^{2}$ for scenario 1, 2, 3, and 4 respectively. Cooling demand is calculated to be $21.4 \mathrm{KWh} / \mathrm{m}^{2}$ for the base case scenario and it is reduced to $10.8 \mathrm{KWh} / \mathrm{m}^{2}, 9.3 \mathrm{KWh} / \mathrm{m}^{2}$, $10.4 \mathrm{KWh} / \mathrm{m}^{2}$ and $10.1 \mathrm{KWh} / \mathrm{m}^{2}$ for scenario 1,2 , 3 , and 4 respectively.

As it can be remarked, both heating and cooling demand are significantly reduced in all scenarios when compared to the base case scenario. The energy demand for heating and cooling is more than halved. The effect of all interventions on the reduction of the heating demand is more intense than the reduction for the cooling demand.

It is also important to note that for the base case and all interventions scenarios urban block 1 presents higher values for both heating and cooling load demand than urban block 2 , which means that the more compact urban block form appears to have a better energy performance in all cases. However, it is important to examine the effect of each one of these interventions on the energy demand of each urban block to assess their efficiency and to compare the scenarios.

\section{a. Thermal insulation scenario}

The comparison between the base case scenario and scenario 1 (thermal insulation scenario) is presented in Table 3. As it is observed for the discontinuous urban block form, the total energy demand is reduced by $55.7 \%$ while, for the continuous urban block form, it is reduced by $57.2 \%$. This

\section{Table 3}

Improvement for the heating and the cooling demand (percentage of reduction) for the discontinuous and the continuous urban block form through the Thermal insulation scenario (1). Comparison to the base case (all floors)

\begin{tabular}{c|c|c|c}
\hline Urban block form & Heating demand & Cooling demand & Total demand \\
\hline Discontinuous & $56.8 \%$ & $48.3 \%$ & $55.7 \%$ \\
\hline Continuous & $58.2 \%$ & $49.5 \%$ & $57.2 \%$ \\
\hline
\end{tabular}

means that the thermal insulation of the building shell can have a stronger effect on the energy efficiency of continuous urban forms. For urban block 2, both the heating and the cooling demand present a larger percentage of reduction in this upgrading intervention scenario. The difference in the percentage reduction of the total energy demand between the discontinuous and the continuous form indicates that the building shells' thermal insulation renovation scenario can, by $1.5 \%$, be more efficient according to the urban blocks form and geometry. 


\section{b. PCM scenario}

The comparison between the base case scenario and scenario 2 (PCM scenario) is presented in Table 4. As it is observed for the discontinuous urban block form, the total energy demand is reduced by $57.5 \%$ while, for the continuous urban block form, it is reduced by $58.7 \%$. This means that the increase in the effect of the thermal mass of the building does not alter the fact that the continuous form presents a higher percentage improvement in comparison to the base case. Both the heating and the cooling demand present a larger percentage of reduction for this upgrading intervention scenario. It is also interesting to note that the PCM can improve the energy performance of thermally insulated urban blocks of discontinuous form by $4.0 \%$ and of continuous urban blocks by $3.5 \%$. This means that increasing thermal mass could be a more effective intervention on insulated discontinuous buildings than on insulated continuous urban blocks.

\begin{tabular}{|c|c|c|c|}
\hline Urban block form & Heating demand & Cooling demand & Total demand \\
\hline Discontinuous & $57.8 \%$ & $55.1 \%$ & $57.5 \%$ \\
\hline Continuous & $59.0 \%$ & $56.4 \%$ & $58.7 \%$ \\
\hline
\end{tabular}

\section{c. Green roof scenario}

The third upgrading scenario consists of the construction of a green roof on the rooftop of all buildings of each examined urban block. As it has been mentioned the $U$-value of the roof is reduced by 0.1 , but the green roof also contributes on the increase of thermal mass of the roof and of the reduction of incident solar radiation. This means that it is expected to reduce further the heating and cooling load demand of the urban block compared to scenario 1. It can be remarked by the percentages presented in Table 5 that the green roof can reduce the heating load demand

\begin{tabular}{c|c|c|c|}
\hline Urban block form & Heating demand & Cooling demand & Total demand \\
\hline Discontinuous & $57.2 \%$ & $51.2 \%$ & $56.5 \%$ \\
\hline Continuous & $58.3 \%$ & $51.5 \%$ & $57.5 \%$ \\
\hline
\end{tabular}

of urban block (UB) 1 (discontinuous) by $57.2 \%$ and of urban block 2 (continuous) by $58.3 \%$ As far as it concerns cooling load demand it is remarked that it is reduced by $51.2 \%$ for UB 1 and by 51.5 $\%$ for UB 2. Finally, the total energy demand is reduced by $56.5 \%$ and by $57.5 \%$ for urban block 1 and 2 respectively.

The comparison of the intervention to the base case scenario shows that this intervention scenario (green roof) can be more effective in the continuous urban block form, but this conclusion is rather forced by the very high effect of the thermal insulation on the reduction of the total energy demand of the urban blocks. The comparison of scenario 1 (thermal insulation) and scenario 3 (green roof)

\begin{tabular}{c|c|c|c}
\hline Urban block form & Heating demand & Cooling demand & Total demand \\
\hline Discontinuous & $1.0 \%$ & $5.6 \%$ & $1.7 \%$ \\
\hline Continuous & $0.2 \%$ & $4.0 \%$ & $0.7 \%$ \\
\hline
\end{tabular}

shows that the energy saving effect of the green roof is $1.7 \%$ for the discontinuous form and $0.7 \%$ for the continuous form, which means that the green roof is more effective on the insulated discontinuous form (Table 6). In fact, this intervention could be considered to have a significant contribution mainly in the cooling load demand as the heating load demand improvement is very small in both cases.

\section{Table 4}

Improvement for the heating and the cooling demand (percentage of reduction) for the discontinuous and the continuous urban block form through the PCM scenario (2). Comparison to the base case (all floors)

\section{Table 5}

Improvement for the heating and cooling demand (percentage of reduction) for the discontinuous and the continuous urban block form through the Green roof scenario (3). Comparison to the base case (all floors)

\section{Table 6}

Improvement for the heating and cooling demand (percentage of reduction) for the discontinuous and the continuous urban block form through the Green roof scenario (3). Comparison to scenario 1 (all floors) 
Table 7

Improvement for the heating and cooling demand (percentage of reduction) for the discontinuous and the continuous urban block form through the Green roof scenario (3). Comparison to scenario 1 (last floor)

\section{Table 8}

Improvement for the heating and the cooling demand (percentage of reduction) for the discontinuous and the continuous urban block, through the Passive solar and shading scenario (4). Comparison to the base case (all floors)

Table 9

Improvement for the heating and the cooling demand (percentage of reduction) for the discontinuous and the continuous urban block, through the Passive solar and shading scenario (4). Comparison to scenario 1 (last floor)
As the effect of the green roof is mostly limited to the last floors' energy demand, it is also interesting to examine the change of the heating and the cooling load only in the last floor of each urban block. The comparison between the last floor of scenario 1 and scenario 3 is presented in Table 7. The improvement in the heating energy demand is 3.5\% for both urban blocks, while the cooling load demand is slightly higher in urban block $2(15.5 \%$ in contrast to $15.2 \%$ of urban block 1). However, when the total energy demand is considered the green roof can provide almost equal improvement for both urban blocks as the difference is less than $0.1 \%$.

\begin{tabular}{|c|c|c|c|}
\hline Urban block form & Heating demand & Cooling demand & Total demand \\
\hline Discontinuous & $3.5 \%$ & $15.2 \%$ & $5.1 \%$ \\
\hline Continuous & $3.5 \%$ & $15.5 \%$ & $5.0 \%$ \\
\hline
\end{tabular}

\section{d. Passive solar and shading scenario}

The effect of sunspaces and shading on the overall energy demand of the urban block is examined. As it is observed by the percentages of improvement of the heating and cooling load demand presented in Table 8 the total load demand improvement of this intervention, compared to the base case scenario, is $56.9 \%$ for the discontinuous urban block and $58.8 \%$ for the continuous urban block.

\begin{tabular}{c|c|c|c|}
\hline Urban block form & Heating demand & Cooling demand & Total demand \\
\hline Discontinuous & $57.7 \%$ & $51.1 \%$ & $56.9 \%$ \\
\hline Continuous & $59.5 \%$ & $53.1 \%$ & $58.8 \%$ \\
\hline
\end{tabular}

The contribution of the sunspaces on the last floor is obviously more important as in this floor, for both examined urban blocks, passive solar gains are significantly increased. The comparison of the last floor's energy demand in the case of scenario 1 (thermal insulation) and scenario 4 (sunspaces) proves that the sunspaces' intervention is far more effective in the continuous urban block form as the reduction of the total energy demand is $13.03 \%$ in comparison to $9.22 \%$ for the discontinuous form (Table 9). It is also important to note that the effect of this intervention scenario in cooling load demand is very important, as it can contribute on the reduction of cooling load

\begin{tabular}{c|c|c|c|}
\hline Urban block form & Heating demand & Cooling demand & Total demand \\
\hline Discontinuous & $7.95 \%$ & $17.58 \%$ & $9.22 \%$ \\
\hline Continuous & $10.14 \%$ & $32.24 \%$ & $13.03 \%$ \\
\hline
\end{tabular}

demand between $17.58 \%$ and $32.24 \%$ for the discontinuous and the continuous form respectively. This reduction is due to shading design which obviously reduces significantly the direct solar radiation, especially in the continuous form (urban block 2) which due to the last floor's recession is far more exposed to direct solar radiation than urban block 1.

\section{Comparative Assessment of the Energy Efficiency of the Interventions}

In this section a comparative analysis of the above-mentioned interventions is described. First, the comparison among the three interventions to scenario 1 (thermal insulation) is presented in order to draw conclusions on the most energy efficient intervention for each period (heating and cooling) and for the whole year period as well. Second, the comparison of the three interventions to scenario 1 is presented according to the urban block form to draw conclusions on the significance of form for the choice of the most efficient intervention. 
The comparison of scenarios 2 (PCM), 3 (Green roof) and 4 (Passive solar) to scenario 1 (Thermal insulation) (Fig. 11) shows that for the heating load demand for UB1 the PCM intervention can provide the higher percentage of reduction. In this case, it is evident that the fact that the other two interventions cannot be installed in all floors is rather decisive. However, for UB2 the most efficient intervention is the construction of sunspaces and shading devices (scenario 4).

For the cooling load demand, it is concluded that for both urban blocks the contribution of PCM is more significant than green roofs and passive solar and shading scenario (Fig. 12 ), as it can provide a decrease between $13.3 \%$ and $13.7 \%$ depending on the form of the urban block. This however might have to do more with the fact that the melting point temperature chosen for the simulation of the PCM $\left(25^{\circ} \mathrm{C}\right)$ favors the phase change of the PCM during the cooling period.

For the whole year period, it is concluded that the results are similar to those for the heating period (Fig. 13), as in the Greek climate heating degree days significantly exceed cooling degree days (Tsikaloudaki, Laskos, and Bikas 2012). Especially in the continuous urban block form, the sunspaces and shading are the most efficient scenario and considering that this intervention can only be installed in the last floor of urban block 1 it can also be considered as a very efficient one in terms of the energy improvement it can provide.

The green roof scenario appears to be more efficient in the case of the discontinuous urban block and this intervention is mostly efficient during the cooling period as it has a very small contribution on the percentage of improvement during the heating period and especially for the continuous form (urban block 1) where the improvement is very small.

It is also remarkable that all three interventions contribute more in the percentage reduction of the cooling load demand, which means that they are expected to be even more efficient in warmer climatic zones of Greece (Zone A and Zone B).

According to the above-mentioned comments, a renovation priority strategy should first target on discontinuous forms of urban
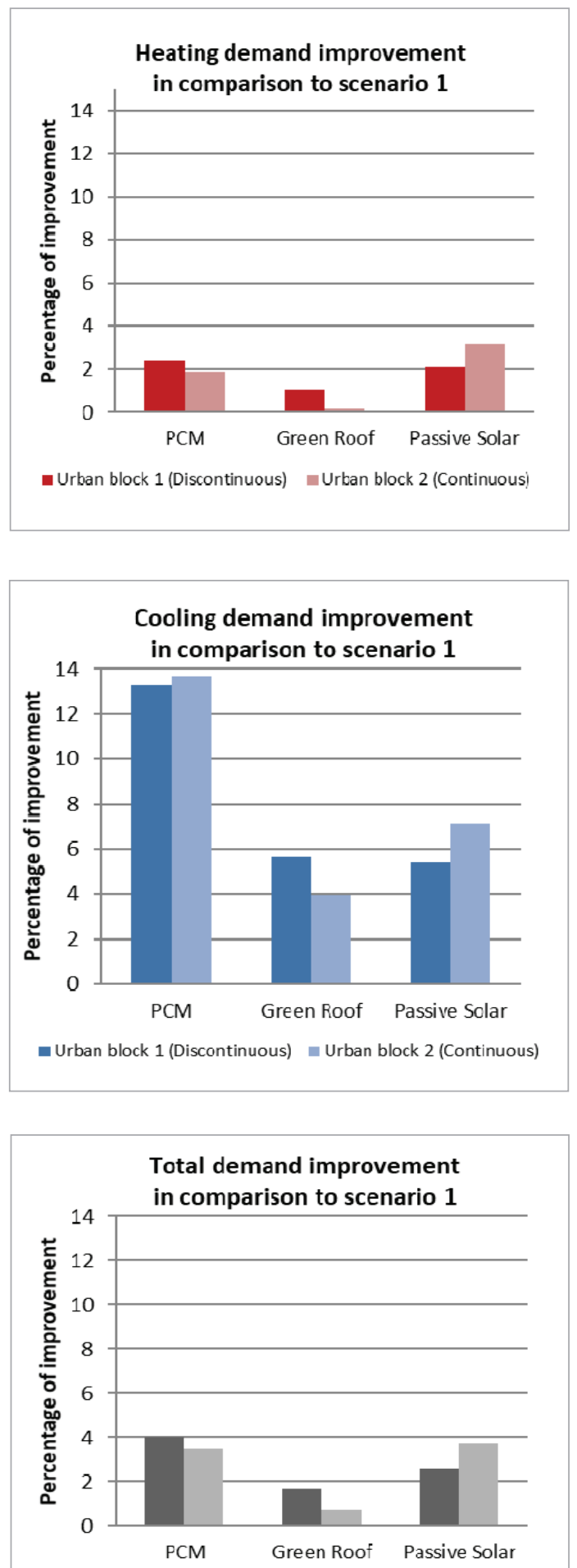

- Urban block 1 (Discontinuous) = Urban block 2 (Continuous)

\section{Fig. 11}

Heating demand improvement (percentage of reduction) of scenarios 2 (PCM), 3 (Green roof) and 4 (Passive solar) in comparison to scenario 1 (Thermal insulation)

Fig. 12

Cooling demand improvement (percentage of reduction) of scenarios 2 (PCM), 3 (Green roof) and 4 (Passive solar) in comparison to scenario 1 (Thermal insulation)

Fig. 13

Total demand improvement (percentage of reduction) of scenarios 2 (PCM), 3 (Green roof) and 4 (Passive solar) in comparison to scenario 1 (Thermal insulation) 
blocks which demand more energy for heating and cooling. However, for already thermally insulated urban blocks, renovation including PCM, green roofs or sunspaces could improve more the efficiency of continuous forms and, among the examined scenarios, the renovation strategy which is more efficient in this case is the passive solar and shading scenario.

In this research four intervention scenarios in two typical urban blocks have been examined, in order to compare renovation strategies in terms of the energy efficiency of the urban blocks and to propose a way to improve city aesthetics at the same time. The results of the research showed that among all the interventions, the most efficient one is the conventional thermal insulation of the building shell. Urban block form and geometry can affect the energy efficiency of the thermal insulation renovation scenario by $1.5 \%$, with the continuous form presenting higher efficiency. This percentage could be translated into thousands of $\mathrm{KW} / \mathrm{h}$ saved, by considering only the difference in urban form. Prioritization of renovation in areas with discontinuous urban block forms could be an effective strategy for the renovation of the existing building stock.

However, it has already been proved by the current energy performance renovation practices that this intervention (e.g. thermal insulation) cannot significantly promote the aesthetic improvement of the Greek city, except if additional measures are also considered for arranging mechanical installations and shading devices in an uniform way.

On the other hand, in most existing buildings increasing the thickness of thermal insulation layer, beyond a certain point, is not feasible considering that there are several limitations of constructional, architectural, or functional nature. For example, increasing wall thickness beyond a certain point is not possible due to the building's position near the plot boundaries. Moreover, it can reduce daylighting access in the interior space or significantly reduce the width of balconies which can in some cases become too narrow to be functional. Therefore, beyond the conventional scenario of thermal insulation, other strategies for improving further the energy performance of buildings should be considered.

Among the other three interventions examined, it is has been proved that the PCM intervention scenario and the passive solar and shading scenario could be the most efficient ones in terms of energy load demand reduction -depending on the form of the urban block- especially for the cooling period where the load demand has been calculated to be significantly improved.

The result of the research cannot be easily compared to existing research on renovation strategies, as in most cases the examination scale of the researches refers at the building scale. This research examined the results in a cumulative perspective assessing the whole energy demand at the urban block scale. The improvement of the passive solar intervention scenario resulted in a reduction of the heating load between $57.7 \%$ and $59.5 \%$. Similar research (Assimakopoulos et al. 2020) for the city of Athens resulted in a range of heating load demand reduction between 35 $\%$ and $60 \%$ according to the examined floor. For the cooling load demand the current research resuted in a reduction between $51.1 \%$ and $53.1 \%$. The research of Asimakopoulos et al. concluded in a range of $32 \%$ to $51 \%$ according to the floor examined. Considering the difference in scale and the difference in climate (Athens belongs to climatic zone B), the results could be considered to be in accordance.

It should be noted that the PCM scenario is, besides the thermal insulation scenario, the only one which can be implemented in all floors, as the passive solar and shading scenario can be implemented only in floors with unobstructed solar radiation while, the green roof can obviously be constructed on the roof of the last floor. PCM research on cooling energy saving is not easy to be compared to the current research results for several reasons. The main reasons are, the scale of the intervention, the building typology used for the simulations and the different melting point and thickness of the examined PCM material. A similar research at the building scale (two storey de- 
tached building) for Athens concluded that the PCM can provide a cooling demand saving between $2.3 \%$ and $3.5 \%$ depending on the PCM melting point temperature (Ascione et al. 2014). The current research concludes in a $13.3 \%$ - $13.7 \%$ improvement which is much higher improvement. This difference can be interpreted by the larger scale of the intervention which seems to optimize the use of PCM and the difference in climate between Athens and Thessaloniki.

Of course, further research is needed in order to define the most efficient strategy for the energy and aesthetic regeneration of the city. It is evident that the efficiency of each renovation strategy depends on several crucial factors which should be taken into account. The efficiency of each intervention scenario should be further examined according to the following factors which might differ significantly in the urban tissue or among different cities.

First, the examination of different road width is essential in a further research as solar gains may vary significantly in case of wider streets. Especially the passive solar and shading scenario which is largely affected by the solar access should be analysed in the case of different width of the streets.

Second, as the climatic conditions are a decisive factor when examining energy efficiency strategies, it is necessary to analyse the examined scenarios for all four climatic zones of Greece.

Third, it should also be mentioned that this study is limited to the examination of one basic orientation for both urban blocks. Results may vary in different orientations as solar access may change according to the street network and the geometry of the urban tissue. Especially, the interventions of scenario 3 could have a significantly different contribution on the energy demand for heating and cooling. An overall strategy for the city regeneration should also take into account all possible orientations at the urban scale.

Fourth, this research examined two typologies of different form. More generalized results demand the further examination of urban typologies at the city scale.

Finally, as all interventions are dependent to the economic cost and the payback period of the initial investment it is also important to examine how these interventions are related to a cost benefit analysis.

The way towards climate neutral cities and the target for nearly zero energy buildings, demand the improvement of the building stock in terms of energy efficiency. The conventional thermal insulation strategies that are mostly applied, despite the important contribution on decreasing heating and cooling energy load demand, should also be combined with other passive energy improvement strategies. These strategies can be a starting point for improving the aesthetic quality of the city. This research proposed an intervention strategy at the urban block scale in order to achieve both energy efficiency and improvement of the aesthetic quality of the city. Total (heating and cooling) demand reduction has been proved that might be reduced between $55.7 \%$ and 58.5 $\%$ according to the intervention scenario chosen. The maximum value corresponds to the passive solar and shading scenario.

Obviously, at the urban block scale it is necessary to consider urban form and urban geometry parameters in order to define the efficiency of the interventions. On the one hand, it has been proved that all interventions cannot be implemented at the same extend, as for example passive solar interventions depend on the solar access and green roofs depend on the available surface which relates to the urban block's geometry. On the other hand, the extent to which each intervention can be implemented could be decisive for the energy performance improvement of the urban block, but in this case other parameters could also be important, as more extensive interventions imply higher investment cost.

This research proved the importance of passive solar and shading strategies on both the improvement of energy efficiency and the city aesthetics. 
The PCM could provide a significant improvement in the energy efficiency ranging from $57.5 \%$ to 58.7 $\%$ according to the urban block form, but as extensive construction works in the interior of buildings should be performed, their application should be carefully considered on a cost benefit analysis.

Green roofs can provide better results in cases where the decrease of cooling demand is a priority as it has been calculated that they can provide a reduction in cooling load demand ranging from 4 to $5.5 \%$ compared to the thermal insulation scenario. However, green roofs can as well promote aesthetics, improve microclimate and citizen's wellbeing, they are considered an important strategy for the quality of life in contemporary cities.

Finally, it has been proved that energy renovation strategies when implemented at the urban block scale (instead of fragmented individual buildings interventions) can contribute not only at the environmental improvement but also at the aesthetic regeneration of the city.

\section{Acknowledgment}

Funding: This research is co-financed by Greece and the European Union (European Social FundESF) through the Operational Programme «Human Resources Development, Education and Lifelong Learning 2014-2020» in the context of the project "Sustainable interventions for the energy and aesthetic improvement of the city" (MIS 5047805)".

\section{References}

Van Oorschot J. A. W. H., Hofman E., Halman J. I. M. Upscaling large scale deep renovation in the Dutch residential sector: A case study. in Energy Procedia; 2016. https://doi.org/10.1016/j.egypro.2016.09.165

European Union. Directive 2012/27/EU of the European Parliament and of the Council of 25 October 2012 on energy efficiency, amending Directives 2009/125/EC and 2010/30/EU and repealing Directives 2004/8/EC and 2006/32/EC. Official Journal of the European Union 2012; vol. L. http://eur-lex.europa.eu/legal-content/EN/ NOT/?uri=CELEX:32012L0027 (2012).

European Union Commission. Commission recommendation (EU) 2016/1318 of 29 July 2016, on guidelines for the promotion of nearly zero-energy buildings and best practices to ensure that, by 2020 , all new buildings are nearly zero-energy buildings. Official Journal of the European Union, 2016.

EPBD. Directive (EU) 2018/844 of the European Parliament and of the Council of 30 May 2018 amending Directive 2010/31/EU on the energy performance of buildings and Directive 2012/27/EU on energy efficiency. Official Journal of the European Union, 2018.

A European Green Deal | European Commission. https://ec.europa.eu/info/strategy/priorities-2019-2024/european-green-deal_en (accessed on August 2021).

Renovation wave | Energy. https://ec.europa. eu/energy/topics/energy-efficiency/energy-efficient-buildings/renovation-wave_en (accessed on August 2021).
R2Cities: Residential Renovation towards nearly zero energy cities. http://r2cities.eu/ (accessed on August 2021).

Renovate Europe. https://www.renovate-europe. eu/ (accessed on August 2021).

CLUE - Climate Neutral Urban Districts in Europe. http://www.clue-project.eu/ (accessed on August 2021).

Tsikaloudaki K., Theodosiou T., Tsirigoti D., Tsoka S., Bikas D., Martinez-Urrutia A., González J. H. Upgrading the building's energy performance with an advanced ventilated façade system. World Review of Science, Technology and Sustainable Development, 2019; (15): 283-299; https://doi.org/10.1504/ WRSTSD.2019.104092

Robust and Reliable technology concepts and business models for triggering deep Renovation of Residential buildings in EU | 4RinEU Project | H2O2O | CORDIS | European Commission. https://cordis. europa.eu/project/id/723829.

Craun Z. Refurbishment as a Sustainable Urban-Design Strategy. Journal of International Affairs, 2012; (65): 157-167.

Sabunas A., Kanapickas A. Estimation of climate change impact on energy consumption in a residential building in Kaunas, Lithuania, using HEED Software. in Energy Procedia 2017; (128): 92-99 (Elsevier Ltd, 2017). https://doi.org/10.1016/j.egypro.2017.09.020

Serghides D. K., Dimitriou S., Katafygiotou M. C., 
Michaelidou M. Energy efficient refurbishment towards nearly zero energy houses, for the Mediterranean region. in Energy Procedia, 2015; (83): 533543. https://doi.org/10.1016/j.egypro.2015.12.173 Karteris M., Theodoridou I., Mallinis G., Tsiros E., Karteris A. Towards a green sustainable strategy for Mediterranean cities: Assessing the benefits of large-scale green roofs implementation in Thessaloniki, Northern Greece, using environmental modelling, GIS and very high spatial resolution remote sensing data. Renewable and Sustainable Energy Reviews 2016; (58): 510-525. https://doi. org/10.1016/j.rser.2015.11.098

Fotopoulou A., Semprini G., Cattani E., Schihin Y., Weyer J., Gulli R., Ferrante A. Deep renovation in existing residential buildings through façade additions: A case study in a typical residential building of the 70s. Energy and Buildings, 2018; (166): 258-270. https://doi.org/10.1016/j.enbuild.2018.01.056

Aksoezen M., Daniel M., Hassler U., Kohler N. Building age as an indicator for energy consumption. Energy and Buildings, 2015. https://doi.org/10.1016/j. enbuild.2014.10.074

Mata É., Sasic Kalagasidis A., Johnsson F. Building-stock aggregation through archetype buildings: France, Germany, Spain and the UK. Building and Environment, 2014; (81): 270-282. https://doi. org/10.1016/j.buildenv.2014.06.013

Caputo P., Costa G., Ferrari S. A supporting method for defining energy strategies in the building sector at urban scale. Energy Policy, 2013; (55): 261-270. https://doi.org/10.1016/j.enpol.2012.12.006

Tsirigoti D., Tsikaloudaki K. The effect of climate conditions on the relation between energy efficiency and urban form. Energies, 2018; $11(3), 582$. https:// doi.org/10.3390/en1 1030582

Ali U., Shamsi M. H., Bohacek M., Hoare C., Purcell K., Mangina E., O'Donnell J. A data-driven approach to optimize urban scale energy retrofit decisions for residential buildings. Applied Energy, 2020. https:// doi.org/10.1016/j.apenergy.2020.114861

Fracastoro G. V., Serraino M. A methodology for assessing the energy performance of large scale building stocks and possible applications. Energy and Buildings, 2011; (43): 844-852. https://doi. org/10.1016/j.enbuild.2010.12.004

Energy renovation of heritage buildings | Interreg Europe. https://www.interregeurope.eu/policylearning/news/9664/energy-renovation-of-heritage-buildings/ (accessed on August 2021).

E2VENT- Energy Efficient Ventilated Facades for Optimal Adaptability and Heat Exchange, H2020 Proj- ect. http://www.e2vent.eu/ (accessed on August 2021).

Ferrante A., Fotopoulou A., Semprini G., Cantelli D., Ruggiero S., Karalis M., Efthymiou C., Papadaki D., Assimakopoulos M. N. IEQ and energy improvement of existing buildings by prefabricated facade additions: The case of a student house in Athens. in IOP Conference Series: Materials Science and Engineering 2019; vol. 609. https://doi.org/10.1088/1757899X/609/4/042047

Mastrucci A., Baume O., Stazi F., Leopold U. Estimating energy savings for the residential building stock of an entire city: A GIS-based statistical downscaling approach applied to Rotterdam. Energy and Buildings, 2014; (75): 358-367. https://doi.org/10.1016/j. enbuild.2014.02.032

Serrano-Jimenez A., Barrios-Padura A., Molina-Huelva M. Towards a feasible strategy in Mediterranean building renovation through a multidisciplinary approach. Sustainable Cities and Society, 2017; (32): 532-546. https://doi. org/10.1016/j.scs.2017.05.002

Rovers R. Building Research \& Information New energy retrofit concept: 'renovation trains' for mass housing, 2014; 42:6, 757-767. https://doi.org/10.10 80/09613218.2014.926764

Greek regulation for the energy performance of buildings, FEK 2367. 2017; (2017).

Tabares-Velasco P. C., Christensen C., Bianchi M. Verification and validation of EnergyPlus phase change material model for opaque wall assemblies. Building and Environment, 2012; (54): 186-196. https://doi.org/10.1016/j.buildenv.2012.02.019

Tsikaloudaki K., Laskos K., Bikas D. On the establishment of climatic zones in Europe with regard to the energy performance of buildings. Energies, 2012; (5): 32-44. https://doi.org/10.3390/ en5010032

Assimakopoulos M. N., De Masi R. F., Fotopoulou A., Papadaki D., Ruggiero S., Semprini G., Vanoli G. P. Holistic approach for energy retrofit with volumetric add-ons toward nZEB target: Case study of a dormitory in Athens. Energy and Buildings, 2020; (207): 109630. https://doi.org/10.1016/j.enbuild.2019.109630

Ascione F., Bianco N., De Masi R. F., de' Rossi F., Vanoli G. P. Energy refurbishment of existing buildings through the use of phase change materials: Energy savings and indoor comfort in the cooling season. Applied Energy, 2014; (113): 990-1007. https://doi. org/10.1016/j.apenergy.2013.08.045 


\section{About the Authors \\ DIMITRA TSIRIGOTI \\ PostDoc researcher \\ Aristotle University of Thessaloniki, Faculty of \\ Engineering, Department of Civil \\ Engineering}

Main research area

Sustainable architecture, Urban morphology, Energy efficiency, Energy renovation, Building construction

\section{Address}

University Campus PO BOX 429 , 54124 Thessaloniki, Greece Tel. 00306977666283

E-mail: dtsirigo@civil.auth.gr

\section{DIMITRIOS ZENGINIS}

PhD Candidate

Aristotle University of Thessaloniki, Faculty of Engineering, Department of Civil Engineering

\section{Main research area}

Energy efficiency, Phase Change Materials (PCM), Building construction

\section{Address}

University Campus PO BOX 429, 54124 Thessaloniki, Greece

Tel. 00306977285829

E-mail: dzengini@civil.auth.gr

\section{DIMITRIOS BIKAS}

Professor Emeritus

Aristotle University of

Thessaloniki, Faculty of

Engineering, Department of Civil Engineering

\section{Main research area}

Sustainable buildings, Building construction, Environmental design and assessment

\section{Address}

University Campus PO BOX 429, 54124 Thessaloniki, Greece Tel. 0030995763

E-mail: bikasd@civil.auth.gr 